\title{
Overlap time is an independent risk factor of radiation pneumonitis for patients treated with simultaneous EGFR-TKI and thoracic radiotherapy
}

\author{
Wenxiao Jia', Qianqian Gao², Min Wang ${ }^{3}$, Ji Li ${ }^{3}$, Wang Jing ${ }^{3}$, Jinming $\mathrm{Yu}^{1,3^{*}}$ and Hui Zhu ${ }^{1,3^{*}}$
}

\begin{abstract}
Background: The exact rate and relevant risk factors of radiation pneumonitis (RP) for non-small-cell cancer (NSCLC) patients treated with the combination of epidermal growth factor receptor-tyrosine kinase inhibitors (EGFR-TKIs) and thoracic radiotherapy have not been reported. Thus, this study aimed to investigate the rate and risk factors of RP for EGFR-positive NSCLC patients simultaneously treated with first-generation EGFR-TKI and TRT.

Patients and methods: We retrospectively evaluated NSCLC patients simultaneously treated with first-generation EGFR-TKI and thoracic radiotherapy between January 2012 and December 2019 at Shandong Cancer Hospital and Institute, Shandong, China. RP was diagnosed via computed tomography and was classified according to the Common Terminology Criteria for Adverse Events v5.0. The risk factors of RP were identified using uni- and multivariate analyses.

Results: Of the 67 patients included, 44.78\% (30/67) developed grade $\geq 2$ RP. Grade $\geq 2$ RP occurred within a median of 3.48 (range 1.07-13.6) months. The EGFR-TKI icotinib, ipsilateral lung V $30>34 \%$, and overlap time of $>20$ days between EGFR-TKI and thoracic radiotherapy were identified to be independent predictive factors of grade $\geq 2$ RP.

Conclusions: Grade $\geq 2$ RP is highly frequent in NSCLC patients simultaneous treated with first-generation EGFR-TKI and thoracic radiotherapy. Icotinib, ipsilateral lung V30 $\leq 34 \%$, and overlap time of $\leq 20$ days for EGFR-TKI and thoracic radiotherapy will be helpful to lower the risk of RP in these patients. The addition of thoracic radiotherapy should be cautious, and the treatment strategies can be optimized to reduce the rate of RP for patients treat with simultaneous EGFR-TKI and thoracic radiotherapy.
\end{abstract}

Keywords: Radiation pneumonitis, EGFR-TKI, Thoracic radiotherapy, Non-small cell lung cancer, Risk factor

\section{Background}

Epidermal growth factor receptor tyrosine kinase inhibitors (EGFR-TKIs) are the standard treatment modality for stage IV NSCLC patients harboring EGFR-sensitive

\footnotetext{
*Correspondence: sdyujinming@163.com; drzhuh@126.com

${ }^{1}$ Department of Radiation Oncology, Shandong Cancer Hospital and Institute Affiliated to Shandong University, Shandong First Medical University, Shandong Academy of Medical Sciences, 440 Jiyan Road, Jinan 250117, Shandong Province, China

Full list of author information is available at the end of the article
}

mutations $[1,2]$. Among these patients, those who progress despite achieving stable disease during treatment are indicated for thoracic radiotherapy (TRT) to improve local control and prognosis. In 2018, Xu et al. found that the addition of consolidative local ablation treatment (LAT) for stage IV EGFR-mutant oligometastatic NSCLC treated with TKI can significantly improve overall survival (40.5 versus 31.5 months, $P<0.001$ ) [3]. This was confirmed in subsequent studies [4-7].

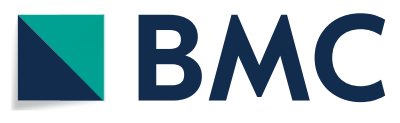

(c) The Author(s) 2021. Open Access This article is licensed under a Creative Commons Attribution 4.0 International License, which permits use, sharing, adaptation, distribution and reproduction in any medium or format, as long as you give appropriate credit to the original author(s) and the source, provide a link to the Creative Commons licence, and indicate if changes were made. The images or other third party material in this article are included in the article's Creative Commons licence, unless indicated otherwise in a credit line to the material. If material is not included in the article's Creative Commons licence and your intended use is not permitted by statutory regulation or exceeds the permitted use, you will need to obtain permission directly from the copyright holder. To view a copy of this licence, visit http://creativecommons.org/licenses/by/4.0/. The Creative Commons Public Domain Dedication waiver (http://creativeco mmons.org/publicdomain/zero/1.0/) applies to the data made available in this article, unless otherwise stated in a credit line to the data. 
However, despite the survival benefit of the combination of radiotherapy and TKI, the occurrence of radiation pneumonitis (RP) cannot be ignored. In 2014, Zhuang et al. reported that $37.5 \%(9 / 24)$ of patients treated with the combination of erlotinib and TRT experience grade $\geq 2$ RP [8]. In our previous study, 63.6\% (7/11) of patients simultaneously treated with TRT and osimertinib, developed grade $\geq 2$ RP [9]. However, despite this high frequency of RP, its exact rate and risk factors among NSCLC patients treated with the combination of EGFR-TKI and TRT have not been completely evaluated. Thus, this study aimed to explore the rate and risk factors of RP for EGFR-mutant NSCLC patients simultaneously treated with first-generation EGFR-TKI and TRT.

\section{Patients and methods}

\section{Study design and patients}

This was a retrospective study of NSCLC patients who were simultaneously treated with EGFR-TKI and TRT at Shandong Cancer Hospital and Institute between January 2012 and December 2019 were retrieved. The inclusion criteria were as follows: (1) stage IIIB-IVB EGFR-mutant NSCLC and (2) first-generation EGFR-TKI was used (gefitinib, erlotinib, and icotinib). Patients with a history of TRT or interstitial lung disease or those treated with immune checkpoint inhibitors were excluded. Simultaneous treatment was defined as at least one day overlap existed between EGFR-TKI and TRT. The overlap time was the days when TRT and EGFR-TKI were conducted simultaneously, and was affected by the duration of TRT, the timing of EGFR-TKI or TRT was added. Data were collected from the medical records. This study was approved by the institutional review board of Shandong Cancer Hospital and Institute and was performed in accordance with the Declaration of Helsinki.

\section{Treatment protocol}

All patients were treated with intensity-modulated radiotherapy and 3-dimensional conformal radiation therapy with photon therapy. Lung dosimetric parameters were extracted from the treatment planning system. Total lung V5 was defined as the percentage of the total lung volume receiving 5 Gy of radiation. Ipsilateral lung V 5 was defined as the percentage of the affected lung volume receiving 5 Gy of radiation. EGFR-TKI treatment comprised gefitinib, erlotinib, or icotinib at $250 \mathrm{mg}$ daily, $150 \mathrm{mg}$ daily, or $125 \mathrm{mg}$ three times daily, respectively.

\section{Diagnosis and classification of radiation pneumonitis}

RP was diagnosed based on patients' symptom, laboratory tests and imaging findings obtained via computed tomography (CT). Follow-up CT images were independently evaluated by two senior radiologists. Differences were resolved by consulting with a third senior radiologist. RP was graded from 1 to 5 according to the Common Terminology Criteria for Adverse Events v5.0 [10]. The grade $1 \mathrm{RP}$ is asymptomatic, only pneumonitis within radiation field and intervention are not indicated; grade $2 \mathrm{RP}$ present the clinical symptoms such as cough with or without expectoration, chest distress, and breathlessness and so on, their activities of daily living (ADL) is limiting mild, the corticosteroids and some symptomatic treatments are administered; the patient with grade 3 RP have severe symptoms, the selfcare ADL is limited, oxygen indicated; patient with grade $4 \mathrm{RP}$ have lifethreatening respiratory compromise, urgent intervention indicated; patient die from grade 5 RP. Clinical symptoms, laboratory tests, treatments, and patient outcomes were included to assess the grade of RP.

\section{Statistical analysis}

Univariate and multivariate analyses using binary logistics regression were conducted to analyze the risk factors of grade $\geq 2$ RP. Categorical variables were included directly in the univariate analysis. Meanwhile, for noncategorical variables, receiver operating characteristic (ROC) curves were first generated to determine the optimal cut-off value. The cut-off value was determined according to the maximum Youden index after considering sensitivity and specificity. Then, the continuous variables were converted to categorical variables. Significant variables in the univariate analysis (i.e., those with a $P$ value of $\leq 0.05$ ) were included in the multivariate analysis. For variables with collinearity, the those with a smaller $P$ value were chosen for multivariate analysis. All statistical analyses were performed using SPSS V26.0 (IBM Corporation, Armonk, NY, USA). A $P$ value of $\leq 0.05$ was considered statistically significant.

\section{Results}

\section{Patient characteristics}

In total, 67 patients were included in the analysis. The clinical characteristics and relevant dosimetric parameters are presented in Table 1 . The median patient age was 53 years (range $37-79$ years). The majority of the patients were female (59.70\%) and had stage IV disease (80.60\%). EGFR exon 19 deletion (44.78\%) and EGFR exon 21 L858R (43.28\%) were the main mutation types. The median follow-up time was 15.27 months. TRT was performed to improve local control in 16 (23.88\%) patients who developed progressive disease (PD) of the primary lesion during EGFR-TKI treatment. Meanwhile, TRT was added for consolidation of the primary lesion in the remaining patients without PD. First-line treatment comprised concurrent first-generation EGFRTKI and TRT in 16 (23.88\%) patients and concurrent 
Table 1 Clinicodemographic patient characteristics

\begin{tabular}{|c|c|}
\hline Factor & $\mathrm{N}(\%)$ \\
\hline \multicolumn{2}{|l|}{ Gender (n) } \\
\hline Male & $27(40.30 \%)$ \\
\hline Female & $40(59.70 \%)$ \\
\hline Age (median, range) (y) & $53.01(36.73-78.35)$ \\
\hline \multicolumn{2}{|l|}{ Smoking history (n) } \\
\hline No & $50(74.63 \%)$ \\
\hline Yes & $17(25.37 \%)$ \\
\hline \multicolumn{2}{|l|}{ T stage in naïve ( $n$ ) } \\
\hline $1-2$ & $43(64.18 \%)$ \\
\hline $3-4$ & $24(35.82 \%)$ \\
\hline \multicolumn{2}{|l|}{ TNM stage (n) } \\
\hline$\|\mathrm{\| B}-\| \mathrm{C}$ & $13(19.40 \%)$ \\
\hline IVA-IVB & $54(80.60 \%)$ \\
\hline \multicolumn{2}{|l|}{ Location (n) } \\
\hline Upper lobe & $21(31.34 \%)$ \\
\hline Middle and lower lobe & $46(68.66 \%)$ \\
\hline \multicolumn{2}{|l|}{ Type of mutation (n) } \\
\hline EGFR exon 19 del & $30(44.78 \%)$ \\
\hline EGFR exon 21 L858R & $29(43.28 \%)$ \\
\hline Others & $8(11.94 \%)$ \\
\hline \multicolumn{2}{|l|}{ Type of EGFR-TKI (n) } \\
\hline Gefitinib & $39(58.21 \%)$ \\
\hline Erlotinib & $17(25.37 \%)$ \\
\hline Icotinib & $11(16.42 \%)$ \\
\hline \multicolumn{2}{|l|}{ The treatment model $(n)$} \\
\hline Simultaneous EGFR-TKI and TRT for first line & $16(23.88 \%)$ \\
\hline $\begin{array}{l}\text { Simultaneous EGFR-TKI, chemotherapy and TRT } \\
\text { for first line }\end{array}$ & $18(26.87 \%)$ \\
\hline $\begin{array}{l}\text { Previous chemotherapy, simultaneous EGFR-TKI } \\
\text { and TRT for second line }\end{array}$ & $33(49.25 \%)$ \\
\hline \multicolumn{2}{|l|}{ Dose fractionation (n) } \\
\hline CFRT & $59(88.06 \%)$ \\
\hline SBRT & $8(11.94 \%)$ \\
\hline Dose per fraction (median, range) (Gy) & $2(2-12)$ \\
\hline Total dose (median, range) (Gy) & $56(39-72)$ \\
\hline GTV (median, range) (ml) & $25.30(0.70-338.80)$ \\
\hline PTV (median, range) (ml) & $133.30(11.40-752.20)$ \\
\hline
\end{tabular}

EGFR-TKI epidermal growth factor receptor tyrosine kinase inhibitor, TRT thoracic radiotherapy, CFRT conventional fractional radiotherapy, SBRT stereotactic body radiation therapy, GTV gross tumor volume, PTV plan tumor volume, RP radiation pneumonitis

first-generation EGFR-TKI, chemotherapy, and TRT in 18 (26.87\%) patients. The $33(49.25 \%)$ patients with previous chemotherapy were treated with simultaneous firstgeneration EGFR-TKI and TRT as second-line treatment.

\section{Incidence of RP}

Overall, 30 of the 67 (44.78\%) patients developed grade $\geq 2$ RP. Among them, $24(35.82 \%)$ patients and 6
(8.96\%) patients had grades 2 and $3 \mathrm{RP}$, respectively. No patient developed grade 4 or $5 \mathrm{RP}$. The median time from the beginning of TRT to the occurrence of grade $\geq 2 \mathrm{RP}$ was 3.48 months (range, 1.07-13.6 months). There were $96.67 \%(29 / 30)$ of the patients who developed grade $\geq 2$ RP within 6 months of the beginning of TRT. Only one patient experienced grade $\geq 2 \mathrm{RP}$ at a later period of 13.6 months. Representative CT images of one patient who developed grade $3 \mathrm{RP}$ are presented in Fig. 1. The patient received a total of 50 Gy in 10 fractions, and the total mean lung dose (MLD), total lung V20, and ipsilateral lung V30 were $8.21 \mathrm{~Gy}, 14.91 \%$, and $19.05 \%$, respectively.

\section{Risk factors of RP Univariate analysis}

As shown in Table 2, the overall risk of grade $\geq 2 \mathrm{RP}$ increased as the lung irradiation dose increased. The total lung V15, V20, V30 and ipsilateral lung V15, V20, and V30 MLD were significantly correlated with grade $\geq 2$ RP. In view of the collinearity of lung radiation dosimetric parameters, the ipsilateral lung V30 was converted as a categorical variable, and the variable with the smallest $P$ value was included in the multivariate analysis.

Aside from the lung radiation dosimetric parameters, other clinical characteristics were also included in the univariate analysis. The results are presented in Table 3. The type of mutation, use of chemotherapy, and timing for the addition of TRT were not associated with RP. Meanwhile, a gross tumor volume (GTV) of $>27 \mathrm{ml}$ (OR 2.77; 95\% CI 1.02-7.49, $P=0.045$ ), PTV $>120 \mathrm{ml}$ (OR 4.03; 95\% CI 1.42-11.43; $P=0.009)$, and ipsilateral lung V30 > 34\% (OR 7.50; 95\% CI 1.48-38.08; $P=0.015$ ) were significantly correlated with grade $\geq 2$ RP. Compared with gefitinib, icotinib was associated with a lower risk of grade $\geq 2$ RP (OR $0.09 ; 95 \%$ CI $0.01-0.74 ; P=0.025$ ). Similar results were obtained for erlotinib versus icotinib. A dose per fraction of $\geq 3$ Gy was also correlated with a lower risk of grade $\geq 2$ PR (OR 0.29; 95\% CI 0.09-0.94; $P=0.039$ ). Further, an overlap time of $>20$ days between first-generation EGFR-TKI and TRT and a TRT duration of $>33$ days were significantly correlated with grade $\geq 2$ RP (OR 8.52; 95\% CI 1.75-41.41; $P=0.008$ and OR 3.05; $95 \%$ CI 1.01-9.21; $P=0.048$, respectively).

\section{Multivariate analysis}

In consideration of the collinearity of some variates, the type of EGFR-TKI, PTV, dose per fraction, overlap time of first-generation EGFR-TKI and TRT, and ipsilateral lung V30 were included in multivariate analysis. The results are presented in Table 3. The type of EGFR-TKI, ipsilateral lung V30, and overlap time of first-generation EGFR-TKI and TRT were independent predictive factors 

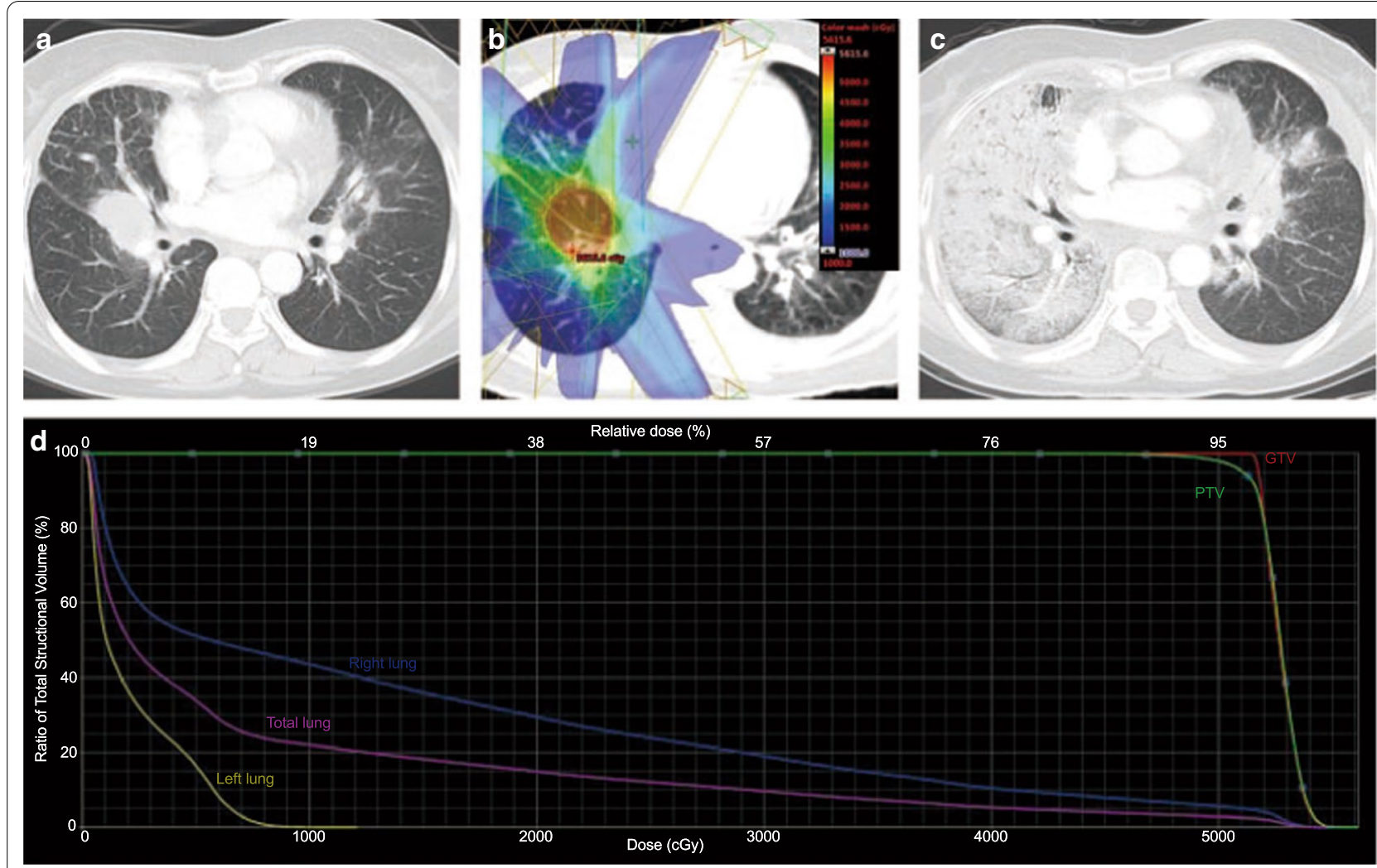

Fig. 1 Representative images of one patient who experienced grade 3 RP after simultaneous first-generation EGFR-TKI and thoracic radiotherapy. a Primary lesion before radiotherapy. $\mathbf{b}$ Isodose curve of the treatment plan. $\mathbf{c}$ Three months after radiotherapy. $\mathbf{d}$ Dose distribution histogram of the total lung, right lung, and left lung

Table 2 Univariate logistic regression analysis of the risk factors of grade $\geq 2$ radiation pneumonitis

\begin{tabular}{lll}
\hline Factor & $\boldsymbol{P}$ value & OR $(\mathbf{9 5} \% \mathbf{C l})$ \\
\hline Total lung V5 & 0.188 & $1.02(0.99-1.06)$ \\
Total lung V10 & 0.069 & $1.02(1.00-1.09)$ \\
Total lung V15 & $\mathbf{0 . 0 4 0}$ & $1.06(1.00-1.13)$ \\
Total lung V20 & $\mathbf{0 . 0 3 6}$ & $1.08(1.01-1.16)$ \\
Total lung V30 & $\mathbf{0 . 0 3 2}$ & $1.11(1.01-1.22)$ \\
Total lung MLD & 0.117 & $1.11(0.98-1.25)$ \\
Ipsilateral lung V5 & 0.090 & $1.02(1.00-1.05)$ \\
Ipsilateral lung V10 & 0.054 & $1.03(1.00-1.06)$ \\
Ipsilateral lung V15 & $\mathbf{0 . 0 2 1}$ & $1.04(1.01-1.08)$ \\
Ipsilateral lung V20 & $\mathbf{0 . 0 1 1}$ & $1.06(1.01-1.10)$ \\
Ipsilateral lung V30 & $\mathbf{0 . 0 0 9}$ & $1.07(1.02-1.13)$ \\
Ipsilateral lung MLD & $\mathbf{0 . 0 3 5}$ & $1.09(1.01-1.17)$ \\
\hline
\end{tabular}

The bold text was some risk factor of RP, which were significantly correlated with $\mathrm{RP}$ and the $p$-value $<0.05$

$M L D$ mean lung dose, $R P$ radiation pneumonitis

of grade $\geq 2$. Icotinib yielded a lower rate of grade $\geq 2$ RP than did gefitinib (OR 0.075 ; 95\% CI $0.007-0.78$;
$P=0.030$ ). Ipsilateral lung V $30 \geq 34 \%$ (OR 7.48; 95\% CI 1.14-49.14; $P=0.036)$ and an overlap time of $>20$ days for first-generation EGFR-TKI and TRT (OR 9.11; 95\% CI $1.67-49.65 ; P=0.011)$ were significantly correlated with grade $\geq 2$ RP. The rates of grade $\geq 2$ by subgroup of type of EGFR-TKI, ipsilateral lung V30, and overlap time of first-generation EGFR-TKI and TRT are shown in Fig. 2. The results showed that compared with gefitinib and erlotinib, icotinib may be a protective factor for RP. Ipsilateral lung V $30 \leq 34 \%$ also yielded a lower rate of grade $\geq 2$ RP than ipsilateral lung V30 $>34 \%$. Further, a shorter overlap time of EGFR-TKI and TRT may help lower the risk of grade $\geq 2 \mathrm{RP}$.

\section{Discussion}

$\mathrm{RP}$ is an important complication of simultaneous treatment with first-generation EGFR-TKI and TRT for EGFR-mutant NSCLC. However, its exact rate and risk factors in this population are unclear. In this study, $44.78 \%$ (30/67) of the patients simultaneously treated with first-generation EGFR-TKI and TRT developed grade $\geq 2$ RP. In univariant analysis, a dose per fraction 
Table 3 Univariate and multivariate logistic regression analyses of the risk factors of grade $\geq \mathbf{2}$ radiation pneumonitis

\begin{tabular}{|c|c|c|c|c|}
\hline \multirow[t]{2}{*}{ Factor } & \multicolumn{2}{|c|}{ Univariate analysis } & \multicolumn{2}{|c|}{ Multivariate analysis } \\
\hline & $P$ value & OR $(95 \% \mathrm{Cl})$ & $P$ value & OR $(95 \% \mathrm{Cl})$ \\
\hline \multicolumn{5}{|l|}{ Gender } \\
\hline \multicolumn{5}{|l|}{ Male } \\
\hline Female & 0.649 & $0.80(0.30-2.12)$ & & \\
\hline \multicolumn{5}{|l|}{ Age (years) } \\
\hline \multicolumn{5}{|l|}{$\leq 65$} \\
\hline$>65$ & 0.146 & $0.42(0.13-1.36)$ & & \\
\hline \multicolumn{5}{|l|}{ T stage in naïve } \\
\hline \multicolumn{5}{|l|}{$\mathrm{T} 1-2$} \\
\hline T3-4 & 0.099 & $2.36(0.85-6.55)$ & & \\
\hline \multicolumn{5}{|l|}{ Type of mutation } \\
\hline Exon 19-del & 0.080 & & & \\
\hline Exon $21 \mathrm{~L} 858 \mathrm{R}$ & 0.141 & $0.45(0.16-1.3)$ & & \\
\hline Others & 0.219 & $3.00(0.52-17.32)$ & & \\
\hline \multicolumn{5}{|l|}{ Type of EGFR-TKI } \\
\hline Gefitinib & 0.081 & & 0.081 & \\
\hline Erlotinib & 0.641 & $0.76(0.24-2.39)$ & 0.808 & $1.18(0.32-4.37)$ \\
\hline Icotinib & 0.025 & $0.09(0.01-0.74)$ & 0.030 & $0.08(0.007-0.78)$ \\
\hline \multicolumn{5}{|l|}{ The treatment model } \\
\hline Simultaneous EGFR-TKI and TRT for first line & 0.448 & & & \\
\hline Simultaneous EGFR-TKI, chemotherapy and TRT for first line & 0.384 & $1.76(0.49-6.34)$ & & \\
\hline Previous chemotherapy, simultaneous EGFR-TKI and TRT for second line & 0.206 & $2.50(0.60-10.34)$ & & \\
\hline \multicolumn{5}{|l|}{ Dose fractionation } \\
\hline \multicolumn{5}{|l|}{ CFRT } \\
\hline SBRT & 0.558 & $1.70(0.29-9.97)$ & & \\
\hline \multicolumn{5}{|l|}{ GTV (ml) } \\
\hline \multicolumn{5}{|l|}{$\leq 27$} \\
\hline$>27$ & 0.045 & $2.77(1.02-7.49)$ & & \\
\hline \multicolumn{5}{|l|}{ PTV (ml) } \\
\hline \multicolumn{5}{|l|}{$\leq 120$} \\
\hline$>120$ & 0.009 & $4.03(1.42-11.43)$ & & \\
\hline \multicolumn{5}{|l|}{ Dose per fraction (Gy) } \\
\hline \multicolumn{5}{|l|}{$<3.00$} \\
\hline$\geq 3.00$ & 0.039 & $0.29(0.09-0.94)$ & & \\
\hline Total dose (Gy) & & & & \\
\hline$\leq 50$ & & & & \\
\hline$>50$ & 0.752 & $0.85(0.30-2.38)$ & & \\
\hline Total dose EQD2 ( $\alpha / \beta=3)(G y)$ & & & & \\
\hline$\leq 55$ & & & & \\
\hline$>55$ & 0.103 & $0.42(0.15-1.19)$ & & \\
\hline Overlap time of EGFR-TKI and TRT (days) & & & & \\
\hline$\leq 20$ & & & & \\
\hline$>20$ & 0.008 & $8.52(1.75-41.41)$ & 0.011 & $9.11(1.67-49.65)$ \\
\hline Duration of TRT (days) & & & & \\
\hline$\leq 33$ & & & & \\
\hline$>33$ & 0.048 & $3.05(1.01-9.21)$ & & \\
\hline Ipsilateral lung V30 (\%) & & & & \\
\hline$\leq 34$ & & & & \\
\hline$>34$ & 0.015 & $7.50(1.48-38.08)$ & 0.036 & $7.48(1.14-49.14)$ \\
\hline Timing of TRT was added & & & & \\
\hline TRT was added after the PD in the maintain of TKI & & & & \\
\hline TRT was added without PD in the maintain of TKI & 0.631 & $1.32(0.43-4.06)$ & & \\
\hline
\end{tabular}


Table 3 (continued)

The bold text was some risk factor of RP, which were significantly correlated with RP and the $p$-value $<0.05$

EGFR-TKI epidermal growth factor receptor tyrosine kinase inhibitor, TRT thoracic radiotherapy, CFRT conventional fractional radiotherapy, SBRT stereotactic body radiation therapy, GTV gross tumor volume, PTV plan tumor volume, RP radiation pneumonitis, $P D$ progressive disease

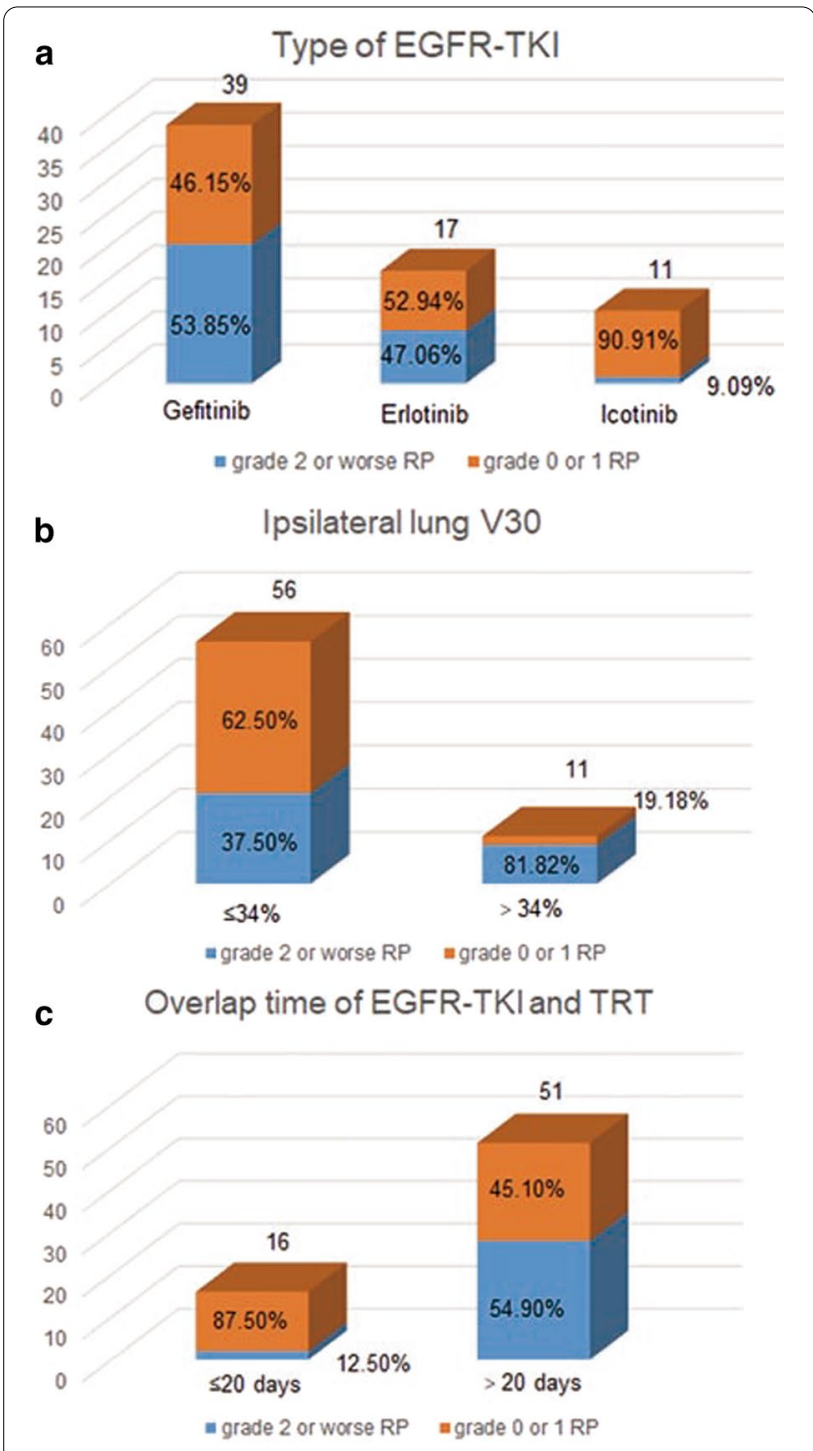

Fig. 2 Rates of radiation pneumonitis by subgroup of a type of EGFR-TKI, $\mathbf{b}$ ipsilateral lung V30, and c overlap time of EGFR-TKI and thoracic radiotherapy

of $\geq 3$ Gy was found to be a protective factor of grade $\geq 2$ PR which is conflict with our knowledge, after correlation analysis, we found the dose per fraction was negative correlation with overlap time and PTV, so we think the result is only a statistical correlation and can be explained by a shorter overlap time and smaller PTV. Through multivariate analysis we found the EGFR-TKIs gefitinib and erlotinib, ipsilateral lung V30>34\%, and overlap time of $>20$ days for EGFR-TKI and thoracic radiotherapy increased the risk of grade $\geq 2 \mathrm{RP}$.

Combination treatment with first-generation EGFRTKI and TRT is being increasingly used owing to its profound prognostic benefit $[3,5,7]$. However, RP has also been frequently reported in this modality [3, 8, 9]. Further, previous phase I clinical trials to explore the safety of simultaneous EGFR-TKI and TRT for unresectable untreated stage III NSCLC harboring EGFR mutations were terminated earlier owe to lung toxicity [11, 12]. Consistent with the findings reported by Zhuang et al. [13], the rate of grade $\geq 2 \mathrm{RP}$ for patients treated with the combination of EGFR-TKI and TRT was higher than that for patients receiving concurrent chemoradiotherapy. Similar findings were reported by Zheng et al. and Chang et al. who reported that $20 \%(2 / 10)$ and $12 \%(3 / 25)$ of their patients developed grade $\geq 3 \mathrm{RP}$ when treated with this modality $[6,14]$.

The high rate of grade $\geq 2$ RP may be explained by some therapeutic mechanisms. First, as the target of EGFR-TKI, EGFR is primarily expressed in alveolar epithelial cells and is important for their proliferation and regeneration. EGFR inhibition suppresses the proliferation of alveolar epithelial cells and prevents their selfrepair in response to radiation damage [15]. Second, erlotinib combined with radiation induces the accumulation of tumor cells in the $G_{1}$ and $G_{2}-M$ phase, resulting in a reduction of them in the $S$ phase. Erlotinib was also found play important roles in apoptosis induction, accelerated cellular repopulation, DNA damage repair, and enhanced radiosensitivity of tumor cells. All these can also increase radiation injury in normal lung tissue [16]. In addition, Harada et al. reported that gefitinib can upregulate important genes, including S100A8, S100A6, and stefinA3. These genes are known to be involved in neutrophil sequestration, acute inflammation, and airway remodeling [17]. Miyake et al. also reported that gefitinib can increase inflammatory cell infiltration and pro-inflammatory cytokine expression and augment pneumonitis [18]. However, further studies are still needed to elucidate the exact mechanism for the high rate of RP in combination treatment with first-generation EGFR-TKI and TRT.

Zhuang et al. reported that the lung dosimetric parameters and PTV are the predictive factors of RP for patients simultaneously treated with EGFR-TKI and TRT [19]. Consistent findings were observed in our study. In this study, we found that type of EGFR-TKI, ipsilateral 
lung V30, and overlap time of first-generation EGFR-TKI and TRT are independent predictive factors for grade 2 or worse RP. Patients treated with icotinib have a lower rate of grade $\geq 2 \mathrm{RP}$ than gefitinib and erlotinib, which is consistent with previous reports that icotinib has a lower rate of adverse events than gefitinib and has the narrowest and safest toxicity spectrum [20, 21]. The broad therapeutic window and high selectivity towards the target EGFR of icotinib may be a reason for the safer toxicity spectrum [22]. Additionally, icotinib is metabolized by several enzymes and has a shorter half-life than other EGFR-TKIs, thus decreasing the accumulation of icotinib [23-25]. This result highlights that icotinib may be a safer choice for simultaneous treatment with TRT. The total lung V20 and MLD have been verified to be reliable biomarkers for predicting the risk of RP $[26,27]$. In this study, we found that the ipsilateral lung V30 is the most powerful predictor of grade $\geq 2 \mathrm{RP}$ in simultaneous treatment with first-generation EGFR-TKI and TRT. An ipsilateral lung V30 of $>34 \%$ was an independent risk factor. An overlap time of $>20$ days for the first-generation EGFR-TKI and TRT was also an independent risk factor. This indicates that a shorter overlap time may be safer. Given that the type of EGFR-TKI and overlap time of EGFR-TKI and TRT were associated with the risk of grade $\geq 2 \mathrm{RP}$, the EGFR-TKI may be responsible for the high rate of grade $\geq 2 \mathrm{RP}$ in this combination treatment.

Despite the related adverse effects, TRT should not be completely ruled out as it remains beneficial for patients who develop disease progression. Possible solutions to mitigate the adverse effects include performing low-dose radiotherapy, using icotinib, or suspending EGFR-TKI treatment during TRT for patients at high risk of RP.

\section{Conclusion}

In conclusion, the frequency of grade $\geq 2 \mathrm{RP}$ is higher in simultaneous EGFR-TKI and TRT treatment than that in concurrent chemoradiotherapy. Icotinib, ipsilateral lung V $30 \leq 34 \%$, and shorter overlap time of $\leq 20$ days for EGFR-TKI and thoracic radiotherapy were protective factors against the risk of RP in these patients. Caution should be exercised in the use of simultaneous TRT and EGFR-TKI, and the treatment strategies can be optimized to reduce the rate of RP for patients treat with simultaneous EGFR-TKI and thoracic radiotherapy.

\footnotetext{
Abbreviations

CT: Computed tomography; EGFR-TKIs: Epidermal growth factor receptortyrosine kinase inhibitors; GTV: Gross tumor volume; LAT: Local ablation treatment; MLD: Mean lung dose; NSCLC: Non-small-cell cancer; PD: Progressive disease; RP: Radiation pneumonitis; ROC: Receiver operating characteristic; TRT :Thoracic radiotherapy.
}

Acknowledgements Not applicable.

\section{Authors' contributions}

WJ: Conceptualization, Data curation, Formal analysis, Writing — original draft. QG: Data curation, Formal analysis, Writing —original draft. MW: Data curation, Methodology, Visualization, Writing —original draft. JL: Data curation, Formal analysis, Validation, Writing —original draft. WJ: Formal analysis, Methodology, Supervision, Writing — - review and editing. JY: Conceptualization, Funding acquisition, Project administration, Writing - review and editing. HZ: Conceptualization, Funding acquisition, Project administration, Writing —-review and editing. All authors read and approved the final manuscript.

\section{Funding}

This work was supported by The Innovation Project of Shandong Academy of Medical Sciences (2019-04), and the Academic Promotion Program of Shandong First Medical University (Grant Number: 2019ZL002); National Key Research and Development Program of China (Grant Number: 2018YFC1313201); National Natural Science Foundation of China (Grant Number: 81972862)

\section{Availability of data and materials}

All data generated or analysed during this study are included in this published article.

\section{Ethics approval and consent to participate}

This study was approved by the institutional review board of Shandong Cancer Hospital and Institute and was performed in accordance with the Declaration of Helsinki.

\section{Consent for publication \\ Agreed.}

\section{Competing interests}

The authors declare that they have no competing interests.

\section{Author details}

${ }^{1}$ Department of Radiation Oncology, Shandong Cancer Hospital and Institute Affiliated to Shandong University, Shandong First Medical University, Shandong Academy of Medical Sciences, 440 Jiyan Road, Jinan 250117, Shandong Province, China. ${ }^{2}$ Department of Obstetrics and Gynecology, Qilu Hospital Affiliated to Shandong University, Jinan 250012, Shandong Province, China. ${ }^{3}$ Department of Radiation Oncology, Shandong Cancer Hospital and Institute Affiliated to Shandong First Medical University, Shandong Academy of Medical Sciences, Jinan 250117, Shandong Province, China.

Received: 6 November 2020 Accepted: 11 February 2021

Published online: 23 February 2021

\section{References}

1. Saijo N. Targeted therapies: tyrosine-kinase inhibitors-new standard for NSCLC therapy. Nat Rev Clin Oncol. 2010;7(11):618-9.

2. NCCN Clinical Practice Guidelines in Oncology Non-Small Cell Lung Cancer Version 6.2020. https://www.nccn.org/professionals/physician_gls/ $\mathrm{pdf} / \mathrm{nscl}$ blocks.pdf. 24 June 2020

3. Xu Q, Zhou F, Liu H, Jiang T, Li X, Xu Y, et al. Consolidative local ablative therapy improves the survival of patients with synchronous oligometastatic NSCLC harboring EGFR activating mutation treated with first-line EGFR-TKIs. JThorac Oncol. 2018:13(9):1383-92.

4. Hu F, Xu J, Zhang B, Li C, Nie W, Gu P, et al. Efficacy of local consolidative therapy for oligometastatic lung adenocarcinoma patients harboring epidermal growth factor receptor mutations. Clin Lung Cancer. 2019;20(1):e81-90.

5. Tang Y, Xia B, Xie R, Xu X, Zhang M, Wu K, et al. Timing in combination with radiotherapy and patterns of disease progression in non-small cell lung cancer treated with EGFR-TKI. Lung Cancer (Amsterdam, Netherlands). 2020;140:65-70.

6. Zheng L, Wang Y, Xu Z, Yang Q, Zhu G, Liao XY, et al. Concurrent EGFR-TKI and thoracic radiotherapy as first-line treatment for stage IV 
non-small cell lung cancer harboring EGFR active mutations. Oncologist. 2019;24(8):1031-e612.

7. Yen YC, Hsu HL, Chang JH, Lin WC, Chang YC, Chang CL, et al. Efficacy of thoracic radiotherapy in patients with stage IIIB-IV epidermal growth factor receptor-mutant lung adenocarcinomas who received and responded to tyrosine kinase inhibitor treatment. Radiother Oncol J Eur Soc Ther Radiol Oncol. 2018;129(1):52-60.

8. Zhuang H, Yuan Z, Chang JY, Wang J, Pang Q, Zhao L, et al. Radiation pneumonitis in patients with non-small-cell lung cancer treated with erlotinib concurrent with thoracic radiotherapy. J Thorac Oncol. 2014;9(6):882-5.

9. Jia W, Guo H, Jing W, Jing X, Li J, Wang M, et al. An especially high rate of radiation pneumonitis observed in patients treated with thoracic radiotherapy and simultaneous osimertinib. Radiother Oncol J Eur Soc Therap Radiol Oncol. 2020;152:96-100.

10. National Institute of Cancer. Common Terminology Criteria for Adverse Events (CTCAE) v5.0. https://ctep.cancer.gov/protocolDevelopment/elect ronic_applications/ctc.htm\#ctc_50.

11. Wan J, Cohen V, Agulnik J, Faria S, Portelance L, Ofiara L, et al. Unexpected high lung toxicity from radiation pneumonitis in a phase I/II trial of concurrent erlotinib with limited field radiation for intermediate prognosis patients with stage III or inoperable stage IIB non-small-cell lung cancer (NSCLC). Int J Radiat Oncol Biol Phys. 2009;75(3):e235.

12. Okamoto I, Takahashi T, Okamoto H, Nakagawa K, Watanabe K, Nakamatsu K, et al. Single-agent gefitinib with concurrent radiotherapy for locally advanced non-small cell lung cancer harboring mutations of the epidermal growth factor receptor. Lung Cancer (Amsterdam, Netherlands). 2011;72(2):199-204.

13. Rodrigues G, Lock M, D'Souza D, Yu E, Van Dyk J. Prediction of radiation pneumonitis by dose-volume histogram parameters in lung cancera systematic review. Radiother Oncol J Eur Soc Ther Radiol Oncol. 2004;71(2):127-38.

14. Chang CC, Chi KH, Kao SJ, Hsu PS, Tsang YW, Chang HJ, et al. Upfront gefitinib/erlotinib treatment followed by concomitant radiotherapy for advanced lung cancer: a mono-institutional experience. Lung Cancer (Amsterdam, Netherlands). 2011;73(2):189-94.

15. Suzuki H, Aoshiba K, Yokohori N, Nagai A. Epidermal growth factor receptor tyrosine kinase inhibition augments a murine model of pulmonary fibrosis. Can Res. 2003;63(16):5054-9.

16. Chinnaiyan P, Huang S, Vallabhaneni G, Armstrong E, Varambally $S$, Tomlins SA, et al. Mechanisms of enhanced radiation response following epidermal growth factor receptor signaling inhibition by erlotinib (Tarceva). Can Res. 2005;65(8):3328-35.

17. Harada C, Kawaguchi T, Ogata-Suetsugu S, Yamada M, Hamada N, Maeyama T, et al. EGFR tyrosine kinase inhibition worsens acute lung injury in mice with repairing airway epithelium. Am J Respir Crit Care Med. 2011;183(6):743-51.
18. Miyake K, Tani K, Kakiuchi S, Suzuka C, Toyoda Y, Kishi J, et al. Epidermal growth factor receptor-tyrosine kinase inhibitor (gefitinib) augments pneumonitis, but attenuates lung fibrosis in response to radiation injury in rats. J Med Investig JMI. 2012;59(1-2):174-85.

19. Zhuang H, Hou H, Yuan Z, Wang J, Pang Q, Zhao L, et al. Preliminary analysis of the risk factors for radiation pneumonitis in patients with non-small-cell lung cancer treated with concurrent erlotinib and thoracic radiotherapy. OncoTargets Ther. 2014;7:807-13.

20. Shi Y, Zhang L, Liu X, Zhou C, Zhang L, Zhang S, et al. Icotinib versus gefitinib in previously treated advanced non-small-cell lung cancer (ICOGEN): a randomised, double-blind phase 3 non-inferiority trial. Lancet Oncol. 2013;14(10):953-61.

21. Zhao Y, Liu J, Cai X, Pan Z, Liu J, Yin W, et al. Efficacy and safety of first line treatments for patients with advanced epidermal growth factor receptor mutated, non-small cell lung cancer: systematic review and network meta-analysis. BMJ. 2019;367:15460.

22. Tan F, Shen X, Wang D, Xie G, Zhang X, Ding L, et al. Icotinib (BPI-2009H), a novel EGFR tyrosine kinase inhibitor, displays potent efficacy in preclinical studies. Lung Cancer (Amsterdam, Netherlands). 2012;76(2):177-82.

23. Liu D, Jiang J, Zhang L, Tan F, Wang Y, Hu P. Metabolite characterization of a novel anti-cancer agent, icotinib, in humans through liquid chromatography/quadrupole time-of-flight tandem mass spectrometry. Rapid Commun Mass Spectrom. 2011;25(15):2131-40.

24. Zhao Q, Shentu J, Xu N, Zhou J, Yang G, Yao Y, et al. Phase I study of icotinib hydrochloride (BPI-2009H), an oral EGFR tyrosine kinase inhibitor, in patients with advanced NSCLC and other solid tumors. Lung Cancer (Amsterdam, Netherlands). 2011;73(2):195-202.

25. Ranson M, Hammond LA, Ferry D, Kris M, Tullo A, Murray PI, et al. ZD1839, a selective oral epidermal growth factor receptor-tyrosine kinase inhibitor, is well tolerated and active in patients with solid, malignant tumors: results of a phase I trial. J Clin Oncol. 2002;20(9):2240-50.

26. Tsujino K, Hirota S, Endo M, Obayashi K, Kotani Y, Satouchi M, et al. Predictive value of dose-volume histogram parameters for predicting radiation pneumonitis after concurrent chemoradiation for lung cancer. Int J Radiat Oncol Biol Phys. 2003;55(1):110-5.

27. Oh D, Ahn YC, Park HC, Lim DH, Han Y. Prediction of radiation pneumonitis following high-dose thoracic radiation therapy by $3 \mathrm{~Gy} /$ fraction for non-small cell lung cancer: analysis of clinical and dosimetric factors. Jpn J Clin Oncol. 2009;39(3):151-7.

\section{Publisher's Note}

Springer Nature remains neutral with regard to jurisdictional claims in published maps and institutional affiliations.

Ready to submit your research? Choose BMC and benefit from:

- fast, convenient online submission

- thorough peer review by experienced researchers in your field

- rapid publication on acceptance

- support for research data, including large and complex data types

- gold Open Access which fosters wider collaboration and increased citations

- maximum visibility for your research: over $100 \mathrm{M}$ website views per year

At BMC, research is always in progress.

Learn more biomedcentral.com/submissions 